\section{(6) OPEN ACCESS}

\begin{abstract}
${ }^{1}$ Centre for Research on Inner City Health, Li Ka Shing Knowledge Institute, Toronto, Ontario, Canada ${ }^{2}$ Bloomberg School of Nursing, University of Toronto, Toronto, Ontario, Canada

${ }^{3}$ Dalla Lana School of Public Health, University of Toronto Toronto, Ontario, Canada ${ }^{4}$ Department of Psychology, Wilfrid Laurier University, Waterloo, Ontario, Canada
\end{abstract}

\section{Correspondence to} Alix Freiler, Centre for Research on Inner City Health, Li Ka Shing Knowledge Institute, 209 Victoria Street, 3rd floor, Toronto, ON, Canada M5C 1N8;

freilera@smh.ca

Received 10 April 2013 Revised 15 July 2013

Accepted 17 July 2013 Published Online First 28 August 2013

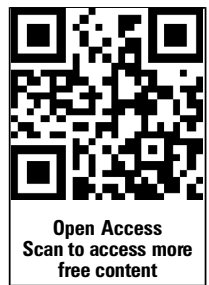

To cite: Freiler $A$, Muntaner C, Shankardass K, et al. J Epidemiol Community Health 2013;67:1068-1072.

\title{
Glossary for the implementation of Health in All Policies (HiAP)
}

\author{
Alix Freiler, ${ }^{1}$ Carles Muntaner, ${ }^{2,3}$ Ketan Shankardass, ${ }^{1,3,4}$ Catherine L Mah, ${ }^{3}$ \\ Agnes Molnar, ${ }^{1}$ Emilie Renahy, ${ }^{1}$ Patricia O'Campo ${ }^{1,3}$
}

\begin{abstract}
Health in All Policies (HiAP) is becoming increasingly popular as a governmental strategy to improve population health by coordinating action across health and non-health sectors. A variety of intersectoral initiatives may be used in HiAP that frame health determinants as the bridge between policies and health outcomes. The purpose of this glossary is to present concepts and terms useful in understanding the implementation of HiAP as a cross-sectoral policy. The concepts presented here were applied and elaborated over the course of case studies of HiAP in multiple jurisdictions, which used key informant interviews and the systematic review of literature to study the implementation of specific HiAP initiatives.
\end{abstract}

\section{INTRODUCTION}

Evidence suggests there is a growing gap in worldwide health inequities. ${ }^{1-6}$ Structural determinants are important in addressing these inequities and particular attention must be paid to the ways in which governments of all levels work to address such issues (including governance). ${ }^{7}$ To narrow widening health inequities worldwide, the 2008 report by the Commission on the Social Determinants of Health recommended that 'policies and programmes must embrace all the key sectors of society not just the health sector' (p. 1). ${ }^{5}$ Health in All Policies (HiAP) is becoming increasingly popular as a governmental strategy to improve population health by coordinating action across health and non-health sectors. ${ }^{8-13}$ A variety of intersectoral initiatives may be used in HiAP that frame health determinants as the bridge between policies and health outcomes.

Public health researchers and practitioners are increasingly expected to study and inform the policy initiatives of government; yet, the complexity of policies and their intended and unintended consequences present major challenges. ${ }^{14}{ }^{15}$ For example, health policies do not always improve population health and not all non-health policies have health effects. ${ }^{16}$ Other glossary contributions have examined healthy public policies, welfare regime concepts, health inequalities, core public administration and policy change theories. ${ }^{17-20}$ Healthy public policies refer to policies that 'improve the conditions under which people live', and include policies implemented by both health and non-health sectors. ${ }^{17}$ Our glossary complements these contributions by proposing a conceptualisation of specific techniques, structures and strategies required to bring sectors together for health equity. In doing so, it addresses three gaps in the previous glossaries. First, it expands upon the dimension of policy implementation introduced in the previous glossary by Smith and Katikireddi; ${ }^{20}$ second, it highlights issues specific to intersectoral action; and third, it reflects theoretical premises that have been empirically refined.

The concepts presented here were applied and elaborated over the course of case studies of HiAP in multiple jurisdictions, which used key informant interviews and the systematic review of literature to study the implementation of specific HiAP initiatives. In particular, realist methods have informed our understanding of how and why certain structures and strategies are useful in implementing $\mathrm{HiAP}^{21-25}$ In addition to enabling researchers and other stakeholders to contribute to the implementation of HiAP initiatives, this glossary also reflects the need for a better understanding of the intersection between a HiAP approach and the study of policy implementation to encourage more rigorous evaluation of these initiatives.

This glossary is described in two parts, as illustrated by figure 1 (underlined terms are defined in the glossary). First, the implementation of HiAP is described as a special case of intersectoral action for healthy public policy where intersectoral engagement is the process for bringing different sectors together in action. Second, intersectoral engagement is driven by strategies and other factors that aim to place HiAP on sectoral agendas (ie, agenda setting) and through the provision of specific resources (ie, capacity building). We discuss two strategies to setting the sectoral agenda, raising awareness of the importance of a HiAP approach, including how each sector can contribute, and using a 'win-win' approach, where sectors stand to gain by using a HiAP approach. In building capacity for sectors to best implement HiAP, there are two considerations: institutional capacity (eg, infrastructure, 'manpower' and financial resources) and expert capacity (eg, expertise and training). Also potentially important in engagement is a sector's prior experience with intersectoral action as this may inform their interest in working on implementing HiAP.

\section{POLICY IMPLEMENTATION \\ Health in All Policies}

A single case of HiAP reflects a multisectoral initiative toward healthy policymaking involving the national or state/provincial level of government where sectors collaborate (often through processes of cooperation, coordination or integration) to develop policies and programmes that include population health initiatives for preventing the manifestation of inequities (ie, 
Figure 1 Relationship among terms related to Health in All Policies (HiAP) implementation.

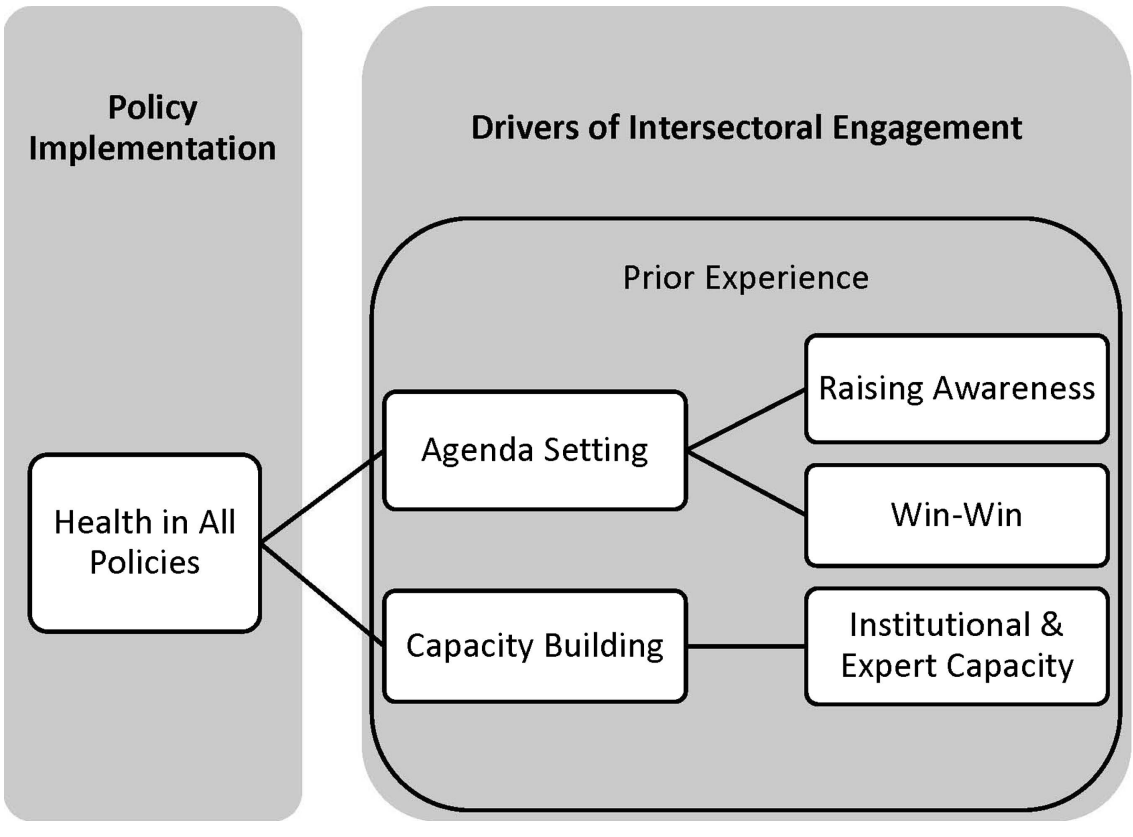

these are initiatives that are not limited to increasing access to primary healthcare; these actions involve impacts on social determinants of health such as education, housing conditions or poverty reduction). Such action could aim to impact equity by targeting marginalised or otherwise dispossessed populations (eg, using means testing) but should also include a universal approach to preventing inequities (ie, across the population at-large). HiAP requires a mechanism for moving beyond the detection of health equity problems (eg, mere health equity impact assessment) to foster remedial action involving an intersectoral response. It is recognised that policies related to $\mathrm{HiAP}$ may foster multiple programmes or projects at multiple levels of context (ie, multiple entry points for the implementation policies and strategies)either directly or indirectly related to the policy commitment. HiAP approaches are distinguishable from other intersectoral initiatives to advance health equity in two important ways. First, HiAP approaches are coordinated primarily by formal structures and mechanisms of governments, although they may include nongovernmental actors, including those from academic, private, and community/civil sectors. Second, initiatives adopted under HiAP approaches are explicitly linked to structural or long-term governmental policies or agendas, rather than being ad hoc in nature.

\section{Intersectoral action}

The concept of intersectoral action developed in several waves, preceding that of HiAP. In 1978, the Alma-Ata Declaration on Primary Health Care called for action by health, social and economic sectors for the 'attainment of the highest possible level of health', leading to the Health for All movement in the 1980s and 1990s. ${ }^{26}$ An early definition originated at the 1997 World Health Organization's Conference on Intersectoral Action for Health:

\footnotetext{
A recognised relationship between part or parts of the health sector with part or parts of another sector which has been formed to take action on an issue to achieve health outcomes (or intermediate health outcomes) in a way that is more effective, efficient or sustainable than could be achieved by the health sector acting alone. ${ }^{27}$
}

Intersectoral action may occur across various levels of government and between governmental and non-governmental sector, and does not necessarily rely on formal structures (ie, committees, legislation). ${ }^{28}$ As a result, they may be ad hoc in nature, unlike the HiAP approach whose design is for long-term endurance. Intersectoral action may be issue-specific (eg, tobacco control) or centred around responding to systemic concerns (eg, overall quality of life). ${ }^{29}$ During HiAP implementation, individual projects may be issue-specific but a HiAP mandate focuses distinctly on addressing systemic considerations (see intersectoral model in Solar et al). ${ }^{30}$

Therefore, if intersectoral action is the coordination of various sectors towards the improvement of health equity, HiAP should be considered the most administratively integrated, formal and systemically-focused form of intersectoral action. Intersectoral action may also be referred to as intersectoral initiatives, intersectoral approach or whole-of-government approach. However, whole-of-government approach implies a horizontal, government-only arrangement, whereas intersectoral action can include both horizontal and vertical relationships as well as non-governmental agencies. ${ }^{31}$

\section{Intersectoral engagement}

The process of recruiting health and non-health sectors to collaborate on policymaking for health outcomes. In many cases, this responsibility may fall on members of the public health or healthcare sectors but special bodies or committees (ie, interministerial or cabinet committees) may also be involved in the process. $^{32} 33$ We draw on the analytic framework of Morestin et $a l,{ }^{34}$ in which they describe the important considerations for government in the implementation of health policy: acceptability and feasibility. Because HiAP necessarily involves multiple sectors, this framework is useful in understanding how to engage sectors given their own concerns. As a result, this approach makes progress towards the implementation of a HiAP approach and relies on strategies, such as agenda setting and capacity building to generate acceptability and feasibility.

\section{Implementation}

The carrying out of a governmental decision as specified by official legislation or formal strategy (ie, mandate). ${ }^{35}$ Mandates signal the beginning of HiAP implementation and may: (1) outline processes and, in some cases, (mandatory) rules for 
healthy policymaking, for example, the use of health impact assessment tools in policy development-mandates could reflect a 'paper strategy' (ie, the initial policy plan) that requires translation in developing processes for healthy policymaking and may be interpreted differently as various actors participate in implementation; (2) allocate or provide guidance on the division of responsibilities for implementation of health policy making processes between specific sectors, other formal structures (eg, committees, quasi-governmental institutes) or levels of government; and (3) allocate resources (broadly) to support processes for healthy policymaking.

\section{DRIVERS OF INTERSECTORAL ENGAGEMENT Agenda setting}

A key process for implementing HiAP requiring the alignment of multiple interests to facilitate 'buy-in' by potential collaborators. This reflects the notion that implementation requires what Morestin et $a l^{34}$ refer to as acceptability. In particular, stakeholders consider the acceptability of both the need for and appropriateness of the policy solution (eg, is the problem important, is the solution logical and one that we can live with), as well as of the legitimacy/accountability and capability of the system within which the policy will be implemented (ie, decisions makers, the decision-making process and the actors involved in implementation).

Agenda setting refers to the process of narrowing issues on which governments focus their attention. ${ }^{37} 38$ The term agenda setting is typically used in the context of the early stages of the policymaking 'cycle' (eg, to encourage the adoption of an initial mandate). We use agenda setting to reflect the need for acceptability of the mandate to be agreed on by the diverse and potentially numerous sectors required to actively participate throughout the implementation of HiAP.

Kingdon argues that the policy process relies on the convergence of three policy streams: problems, politics and policy. Therefore, understanding how to shape the problem can be particularly effective in engaging political actors. ${ }^{39}$ Ultimately, acceptability of HiAP by non-health sectors may be gained by defining the problem in a particular way. As Stone notes:

$[\mathrm{P}]$ roblem definition is never simply a matter of defining goals and measuring our distance from them. It is rather the strategic representation of situations... Representations of a problem are therefore constructed to win the most people to one's side and the most leverage over one's opponents (original emphasis) (p. 106-7). ${ }^{40}$

Therefore, understanding each sector's needs and culture may be crucial to frame the need for HiAP in a way that places it on their agenda. ${ }^{32}$ For example, while some sectors may share the value of equity (eg, in a sector devoted to providing social services), others may be more concerned with compatible goals, like social sustainability. As a result, agenda setting may require problem definition to occur uniquely for different sectors and levels of government, and it may be fostered as a result of greater awareness or a range of contextual factors (eg, political orientation of a government or in relation to a prior experience with health or sustainability). The way in which the problem is defined or framed may contribute to whether a HiAP approach is prioritised by non-health sectors or whether it winds up on their agendas at all. Therefore, setting the agenda may entail agreement on values associated with the mandate (eg, in terms of a health equity or social sustainability agenda), achieved by raising awareness, or finding other ways to motivate buy-in to the mandate, such as using a win-win approach.

\section{Raising awareness}

Raising awareness, specifically, refers to the need and reasons for an intersectoral approach to address health equity articulated to potential participants in order to set a HiAP agenda. ${ }^{10}{ }^{11}$ For example, awareness may be raised on the contributions of non-health sectors to public health outcomes or, alternatively, sectors' influence on health. ${ }^{11}$ In South Australia, several awareness-raising strategies were used to engage non-health sectors, such as using their 2004 South Australia Strategic Plan targets to assess health impacts and intersectoral workshops exploring the potential links between strategic plan targets and individual sectors. ${ }^{9}$ While an awarenessraising strategy may, in some cases, boost HiAP higher on sectors' agendas, it may not lead to the acceptability of a HiAP approach, which may depend on a sector's familiarity and/or comfort with intersectoral action or health equity (see Prior experience section) as well as the feasibility of implementation for individual sectors.

\section{Win-win approach}

Alternatively, employing a win-win approach (also referred to as mutual gains and cobenefits) may be more effective in engaging certain non-health sectors to implement HiAP, where ' $(t)$ he goal is to achieve health gains but not to diminish the primary intention of various sectors or agencies. The aim is to look at expected health gains, but also, for example, social and economic gains' (p. 12). ${ }^{12}$ This strategy is useful where there is no simple agreement on values associated with the mandate (eg, in terms of a health equity or social sustainability agenda) and where agenda setting is facilitated by appealing to non-health interests (eg, sectoral efficiencies), ultimately, leading to the acceptability of a HiAP strategy. In essence, the win-win approach should demonstrate that through addressing health considerations, non-health sectors can still invest full attention in their own agendas, yet achieve both health and non-health benefits for populations. Krech describes this approach as a form of 'health diplomacy' 'to make the healthier choice the easier choice for policy makers'. ${ }^{41}$ This is in contrast to the notion that more directive approaches to agenda setting can lead others to view the health sector as 'imperialists'. ${ }^{42}$ Others note that this may involve tradeoffs in short-term goals and values to foster durable relations with increasingly health-aware partners. ${ }^{103243}$

\section{Capacity building}

A key process for implementing HiAP contingent on the presence of appropriate and/or adequate human, information, financial or infrastructural resources for implementation of a HiAP strategy. This reflects the notion that implementation requires what Morestin et $a l^{34}$ refer to as feasibility. In particular, actors may consider institutional and expert realities of implementing a HiAP strategy (eg, do actors know what to do and how to do it, and do they have the financial, infrastructural or human resources to do it).

While some of these resources may be present for implementation by design (ie, implementation as it was originally conceived), other resources may be required to deal with challenges that emerge in the course of implementing HiAP, which suggests an ongoing process of capacity building. For example, the context of frequent human resources transitions in public sector bureaucracies may result in poor 'institutional memory' within a particular staff team for intersectoral implementation processes.

\section{Institutional capacity}

A dimension of capacity building related to the need for appropriate/adequate resources to support the development and 
implementation of HiAP, including: (1) processes for healthy policymaking that may need to be developed in order to meet the objectives of the mandate, such as the adoption of a health impact assessment tool to facilitate cross-sectoral consultation during policy development; (2) civil servants and experts to carry out day-to-day activities related to processes for healthy policymaking (human resources as 'manpower'); (3) knowledge of or training in how to use resources appropriately (see Expert capacity section); (4) infrastructure for facilitating processes for healthy policymaking, such as websites containing informational resources and 'bricks and mortar'; and (5) financial resources to support various aspects of processes for healthy policymaking. In particular, the availability of financial resources may also signal the importance of a HiAP strategy and encourage cross-sectoral commitment (read: acceptability), which may (in turn) lead to the availability of other aspects of institutional or expert capacity.

Institutional capacity is strengthened by the way in which the mandate is structured, specifically: (1) in using existing systems or structures (or automaticity); (2) its consistency with applicable/ appropriate legislation (or conformity); and (3) when the governmental body initiating, financing or authorising a policy is also being involved in its implementation (or directness). ${ }^{3435} 44$

\section{Expert capacity}

A dimension of institutional capacity related to the need for appropriate/adequate resources to develop and implement processes for healthy policymaking, including: (1) politicians and civil servants within sectors possessing the expertise or knowledge to collaborate on healthy policymaking processes (human resources as 'staff expertise'), including to support the use of tools for healthy policymaking, like health impact assessment, (2) to train staff (ie, civil servants within sectors) about the processes for healthy policymaking (eg, the use of health impact assessment tools in policy development) and (3) to support staff in decision-making through the provision of evidence and analysis (eg, informational resources about the potential health impacts of road development or the possible applications of health impact assessment, respectively). As a result, expert capacity strengthens the overall operation of implementation when specific resources are made available, such as personnel, material resources and technology. 3545

\section{Prior experience}

A dimension of intersectoral engagement where previous involvement with activities related to healthy policymaking and/ or intersectoral action may facilitate agenda setting or capacity building and, ultimately, increased acceptability of the values associated with a HiAP strategy and/or increased knowledge of technical aspects of implementation (ie, expert capacity). For example, prior experience may be relevant where activities involved adherence to similarly intersectoral values (eg, in working toward social sustainability) or required similarly intersectoral solutions (eg, in using environmental impact assessment). Prior experience may also facilitate implementation because of a sector's familiarity with the structural aspects of HiAP (see conformity and automaticity under Institutional capacity section).

\section{Acknowledgements The authors gratefully acknowledge Alex St. John for his contributions to the analyses and write up of the case studies and the support of Peterborough KM Hunter Charitable Foundation.}

Contributors This glossary was jointly conceived by AF, CMun and KS. AF wrote the first draft of the glossary and CMun, KS, CLMah, AM and POC contributed to the editing. CMun and ER suggested using a visual framework. ER was involved in the earlier stages of glossary conceptualisation. AF, CMun, KS, CLMah and POC contributed to the revisions.
Funding This work was supported by Canadian Institute of Health Research grant numbers 111608 and 96566 and the Ontario Ministry of Health and Long-Term Care.

\section{Competing interests None.}

Ethics approval Research Ethics Board, St. Michaels Hospital.

Provenance and peer review Not commissioned; externally peer reviewed.

Open Access This is an Open Access article distributed in accordance with the Creative Commons Attribution Non Commercial (CC BY-NC 3.0) license, which permits others to distribute, remix, adapt, build upon this work non-commercially, and license their derivative works on different terms, provided the original work is properly cited and the use is non-commercial. See: http://creativecommons.org/ licenses/by-nc/3.0/

\section{REFERENCES}

1 Bierman AS. ed. Project for an Ontario Women's Health Evidence-Based Report. Volume 1. Toronto, 2009.

2 Bierman AS. ed. Project for an Ontario Women's Health Evidence-Based Report: Volume 2. Toronto, 2010.

3 Brownwell M, Lix L, Ekuma O, et al. Why is the health status of some manitobans not improving? The widening gap in the health status of manitobans. Winnipeg: Manitoba Centre for Health Policy, 2003.

4 Health Disparities Task Group of the Federal/Provincial/Territorial Advisory Committee on Population Health and Health Security, Reducing Health Disparities Roles of the Health Sector: Discussion Paper, Public Health Agency of Canada: Ottawa, 2004.

5 CSDH. Closing the gap in a generation: Health equity through action on the social determinants of health. Final Report of the Commission on Social Determinants of Health. 2008. www.who.int/social_determinants/thecommission/finalreport/en/index. html (accessed 14 Dec 2012).

6 Mackenbach JP, Bos V, Andersen 0, et al. Widening socioeconomic inequalities in mortality in six Western European countries. Int J Epidemiol 2003;32: 830-7.

7 Solar 0 , Irwin A. A conceptual framework for action on the social determinants of health [Internet]. 2007. http://www.who.int/social_determinants/resources/csdh_ framework_action_05_07.pdf (accessed 30 Jan 2013).

8 Kickbusch I. ed. Health in All Policies. Bulletin 2008;5:56.

9 Lawless A, Williams C, Hurley C, et al. Health in All policies: evaluating the South Australian approach to intersectoral action for health. Can J Public Health 2012;103 (Suppl 1):S15-19.

10 Health in All Policies. Prospects and potentials. Helsinki: Ministry of Social Affairs and Health and European Observatory on Health Systems and Policies, 2006.

11 Howard R, Gunther S. Health in all policies: an EU literature review 2006-2011 and interviews with key stakeholders [Internet]. 2012, 48. http://www. equitychannel.net/uploads/HiAP\%20\%20Final\%20Report\%20May\%202012.pdf (accessed 14 Dec 2012)

12 Ollila E. Health in all policies: from rhetoric to action. Scand J Public Health 2011;39(Suppl 6):11-18.

13 Kickbusch I, Buckett K. eds. Implementing health in all policies: adelaide 2010. Adelaide: Government of South Australia, 2010.

14 Buse C. Intersectoral action for health equity as it relates to climate change in Canada: contributions from critical systems heuristics. J Eval Clin Pract 27 Jun 2013 [Epub ahead of print].

15 Signal LN, Walton MD, Mhurchu CN, et al. Tackling 'wicked' health promotion problems: a New Zealand case study. Health Promot Int 2013;28:84-94.

16 Álvarez-Dardet C. [The role of epidemiology in policy definition. Toward the public health required. 2008 SESPAS Report]. Gac Sanit 200822(Suppl 1): 8-13.

17 Milio N. Glossary: healthy public policy. J Epidemiol Community Health 2001:55:622-3.

18 Eikemo TA, Bambra C. The welfare state: a glossary for public health. J Epidemiol Community Health 2008;62:3-6.

19 Kawachi I, Subramanian SV, Almeida-Filho N. A glossary for health inequalities. J Epidemiol Community Health 2002;56:647-52.

20 Smith KE, Katikireddi SV. A glossary of theories for understanding policymaking. J Epidemiol Community Health 2013;67:198-202

21 Greenhalgh T, Wong G, Westhorp G, et al. Protocol—realist and meta-narrative evidence synthesis: Evolving Standards (RAMESES). BMC Med Res Methodol 2011;11:115.

22 Jagosh J, Macaulay AC, Pluye $P$, et al. Uncovering the benefits of participatory research: implications of a realist review for health research and practice. Milbank $Q$ 2012;90:311-46

23 Jagosh J, Pluye P, Macaulay AC, et al. Assessing the outcomes of participatory research: protocol for identifying, selecting, appraising and synthesizing the literature for realist review. Implement Sci 2011;6:24.

24 Wong G, Greenhalgh T, Westhorp G, et al. Realist methods in medical education research: what are they and what can they contribute? Med Educ 2012;46: 89-96. 
25 Shankardass K, Solar 0, Murphy K, et al. A scoping review of intersectoral action for health equity involving governments. Int J Public Health (Special Issue: Intersectoral action to address the social determinants of health). 2012:57: 25-33.

26 Declaration of Alma-Ata. Alma-Ata, USSR, 1978. http://www.who.int/publications/ almaata_declaration_en.pdf (accessed 1 Mar 2013)

27 World Health Organization. Report of a Conference on Intersectoral Action for Health: A Cornerstone for Health-for-all in the Twenty-first Century; 20-23 April 1997, Halifax, Nova Scotia, Canada, World Health Organization, 1997.

28 Public Health Agency of Canada. Health equity through intersectoral action: an analysis of 18 country case studies. Ottawa: World Health Organization, Ministry of Health, 2008.

29 World Health Organization, Expert consultation: impact assessment as a tool for multisectoral action for health. Kobe, Japan, 2012.

30 Solar O, Valentine N, Rice M, et al. Moving forward to equity in health: what kind of Intersectoral action is needed? An approach to an intersectoral typology. Nairobi, Kenya 2009. http://www.gchp7.info/resources/downloads/t4.pdf (accessed 2 Apr 2013)

31 Public Health Agency of Canada. Section 2: definitions and scoping review of the literature. 2009. http://www.phac-aspc.gc.ca/publicat/2009/ActNowBC/ section2-partie2-eng.php (accessed 19 Jun 2013)

32 World Health Organization. Discussion Paper: Intersectoral Action on Health: A Path for Policy-Makers to Implement Effective and Sustainable Intersectoral Action on Health. Moscow, Russia, 2011

33 Barr V, Pedersen S, Pennock $M$, et al. Health equity through intersectoral action: an analysis of 18 country case studies, 2008. http://www.phac-aspc.gc.ca/publicat/ 2008/hetia18-esgai18/pdf/hetia18-esgai18-eng.pdf (accessed 14 Dec 2012).
34 Morestin F, Gauvin F-P, Hogue M-C, et al. Method for synthesizing knowledge about public policies. Quebec City, QC: National Collaborating Centre for Healthy Public Policy, 2010:65

35 Sabatier P, Mazmanian D. The implementation of public policy: a framework of analysis. Policy Stud J 1980;8:538-60.

36 Theodoulou SZ, Kofinis C. The art of the game with infotrac: understanding American public policy making. Wadsworth/Thomson Learning, 2004.

37 Kingdon JW. Agendas, alternatives and public policies. Harper Collins College Publishers, 1995.

38 Cobb RW, Ross MH. Agenda setting and the denial of agenda access: key concepts In: Ross RW, Cobb MH, eds. Cultural strategies of agenda denial. Lawrence, KS: University Press of Kansas, 1997:3-24.

39 Kingdon JW. Agendas, alternatives, and public policies. Little, Brown; 1984

40 Stone DA. Policy paradox and political reason. Scott Foresman \& Co, 1988.

41 Krech R. Healthy public policies: looking ahead. Health Promot Int 2011; 26(Suppl 2):ii268-72.

42 Nutbeam D. Inter-sectoral action for health: making it work. Health Promot Int 1994;9:143-4.

43 Van Herten LM, Reijneveld SA, Gunning-Schepers LJ. Rationalising chances of success in intersectoral health policy making. J Epidemiol Community Health 2001;55:342-7.

44 Salamon LM. The new governance and the tools of public action: an introduction Fordham Urban Law J 2000;28:1611-74.

45 Dobrow MJ, Goel V, Upshur REG. Evidence-based health policy: context and utilisation. Soc Sci Med 2004:58:207-17. 